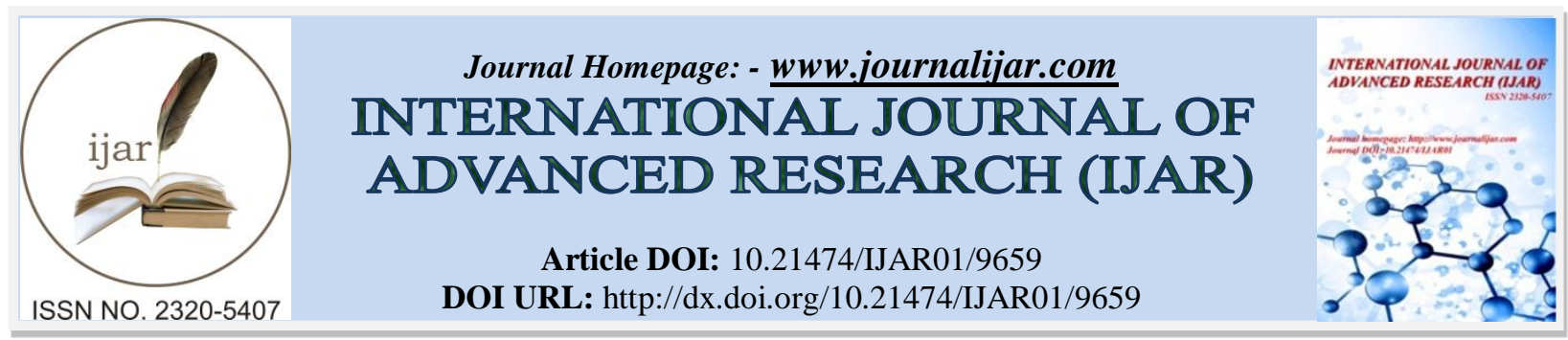

RESEARCH ARTICLE

\title{
THE ROLE OF GROUP IDENTIFICATION IN THE PSYCHOLOGICAL SUPPORT FOR FAMILY MEMBERS OF MILITARY PERSONNEL PARTICIPATING IN PEACEKEEPING ACTIVITY.
}

\author{
A.Issimova and K.Akshulakov. \\ Military Scientific Research Center of the National Defense University named after the First President of the \\ Republic of Kazakhstan - Elbasy, c.Nur-Sultan, Kazakhstan.
}

\section{Manuscript Info}

Manuscript History

Received: 04 July 2019

Final Accepted: 06 August 2019

Published: September 2019

Key words:-

peacekeeping activity, stress, family, group identification.

\section{Abstract}

Background and aim of the study: There is an analysis of influence a military personnel's participation in a peacekeeping activity on family members.

The aim of the study: to examine whether military personnel's movement to another country has a negatively affect to family members; to find an effective method of psychological support for military family.

Materials and methods: In the study, the following scientific methods have been used: analysis, synthesis, comparison, questionnaire and statistical analysis.

Results: The results of the present study suggest that military personnel's participation to a peacekeeping activity impacts on their family member by increase their stress level. Specifically, stress affects on their emotional stability and controllability awareness. Exploring the features of the subject, there conclude that a group identification is an effective method for tackling the question that increases a sense of support, which is a basic factor in reducing their stress level.

Conclusion: In spite of military personnel's participation to a peacekeeping activity has a negative affect to family, group identification based psychological support for military personnel's family is an effective way to resist such a question related stressors.

Copy Right, IJAR, 2019,. All rights reserved.

\section{Introduction:-}

Although a peacekeeping activity has a positive effect to a military personnel [1], studies have found that there are negative effects from the operations to their family members [2]. The positive effects are making additional money, helping to other people, travelling, learning another culture, comparison two countries and recognizing advantage of standard of living own country. However, there are identified the negative effects to soldiers that may affect to their family, such as: away from the family, decrease family identity, military service related stress. Military service in itself is one of the job types that are susceptible to stress which is impacts on family functioning. «Stress» has been defined by Lazarus and Folkman (1984) as «a relationship between the person and the environment that is appraised by the person as taxing or exceeding his or her resources and endangering his or her well-being» [3]. In contrast, from military perspective «stress» has described by Bartone (1998), that «refers to events or forces in the environment, and not from within the person» [4].

\section{Corresponding Author:-A.Issimova.}

Address:-Military Scientific Research Center of the National Defense University named after the First President of the Republic of Kazakhstan - Elbasv. c. Nur-Sultan. Kazakhstan. 
The theoretical analysis have shown that contribution of peacekeeping related stress in family members might depends on periods of deployment, their single or married status and individual characteristics. For instance, Gewirts et al. (2011) found that there are three periods of deployment is associated with family stress: the first, in the pre-deployment period, family stressors is linked with preparation for deployment that may involve anticipatory worry and tension, impending separation. The second is deployment period when families face the stress of prolonged separation and single parenting while the deployed parent is absent. The last post-deployment period could bring additional challenges for two-parent families in re-establishing a parenting 'equilibrium' upon the service member's return [2].

This point confirmed with findings demonstrated by Pincus et al. (1999) that conclude, peacekeeping deployment affect to family stability has an association with a deployment period. For example, in a pre-deployment period, family members might feel anger and protest; emotional detachment and face marital disagreement that linked with increase stress level. In a deployment period, they might have an emotional destabilization and disorganization, sadness, depression, disorientation. Furthermore, anxiety, loneliness, sleeps disturbances, health complains and financial problems are questions that they would face in this period too. The reunion period's issue is mainly related to apprehension over redefined roles and power dynamics. The last post-deployment period, family members could feel resentment over loss of independence; insecurity about place in reconfigured system; service member may have difficulty disengaging from mission orientation [5].

Interestingly, there are findings about the differential impact upon military personnel is associated with their status. That means, single military personnel showed more likely to report chain of command issues as a negative consequence of the deployment whereas, married soldiers were more likely to report that being away from family, missing as the most negative consequence of deployment. Studies found that peacekeeping deployment affects single soldiers more positively than married soldiers (82\% and $72 \%)$ [1].

In addition, with regard to deployment affect, Wiens and Boss (2006) indicated that families without unit affiliation, as well as young and inexperienced families, are often at risk. Military personnel who deploy leave behind a family that does not have the same level of unit organizational or community support as a family [6].

However, from social psychological perspective individual's susceptibility to stress not depends on their status and experienced family level, but it is related to their identity level [7] .

The effects of peacekeeping deployment on military personnel that affect to their family are clear; finding methods for psychological support to reduce their stress is a one of the significant questions at present. There are several reasons of this. The first, it is true that family is a central component for family functions and member's behavior coping with stress. 'Family functioning' is defined as 'the ability to adapt to stress and the ability to reduce family and it's members susceptibility and vulnerability to stress" [8]. The second, there is a positive correlation between psychological support and family member's well-being. To illustrate this, Baider et al.'s study (2003) showed that individual's stress is directly related to their family support level. They identify couples who were experiencing high psychological stress reported lower levels of perceived family support than the normal levels of stress [9]. Thus, keeping family's well-being has a significance for member's identity and support level that is positively associated with not contribution of stress. Whereas, according to a social identity theory when members perceive a less support from a group that they are belong to may reduce their power to resist a stressors, including military personnel's participation to a peacekeeping that affects to their family.

In addition, Kraskovskaia and Racu (2017) conducting research with individual's personal characteristics and stress conclude that, military personnel with low levels of stress, a high level of adaptive abilities, and absence of accentuation and depressive states [10]. Th conclusion is not only plays a key role for military personnel, but it has an importance for family members to adapt a new situation.

Analyzing the existing experiences, it has shown that there are several approaches of psychological support for military family. For instance, Australian military system prepares family members in order to prevent from stress for both separation from the military personnel and his return from the mission. In contrast, the Serbian Armed Force's psychologists from the General Staff Human Resources Department pay particular attention to possible personal and family problems and those personality aspects that linked with their successful interpersonal relations [11]. 
In comparison, Canadian Defense Force psychologist's emphasis psycho-education with members of family to prepare them management their stress more effectively [12]. However, US military peacekeeper's, positive homecoming experiences are associated with military personnel's lower levels of stress that is directly related to their family functioning [13].

In addition, UK military system has intention to promote a sense of community and facilitate stable interpersonal relationships to maintain the informal networks, which appear to be beneficial [14].

The experience of psychological support in Kazakhstan shows that there are mainly focused on military personnel's pre and post peacekeeping deployment diagnosis. Generally, there provide individual psychological support for family members whose have a particular question for psychological help.

In spite of studies have found several ways of psychological support by coping with stress, the previous finding has conclude that social (group) identification is an more effective method to cope with stress that is impacted on individual's family functioning $(\mathrm{p}<0.05)$ [7]. "Social identification" has been defined by Taifel $(1978)$ as "an individual's self-concept which derives from his knowledge of his membership" [15]. According to research in a social-psychological perspective, a group (social) identification is 'central to people's experiences of and reactions to, social and environmental stressors' [16]. Moreover, as outlined above, when individuals categorize as one group they perceive themselves as part of that group and this increases their feeling of supported which is a significant variable for stress buffering. Thus, group (social) identification might be an effective method for psychological support for family of military personnel, participating in peacekeeping activity, by overcoming and preventing from a variety of their peacekeeping related stress reactions as anxiety, depression ext. A study by Mansfield (2010) with 250000 married couples, who found that the situation associated with military personnel's participation in peacekeeping operation affects to a psychological state of the family that includes anxiety, problems emotional disorders as depression, sleep disorders [17]. A similar scientific approach is also made by M.Raju (2014), where the adverse effects of the participation of the military in the peacekeeping mission on the family members divided into three stages, until military personnel's participation in peacekeeping activitity stage is associated with family member's aggression; in a period of peacekeeping deployment they have reliance on depression and support, and the reflection of certain forms of feeling during peacemaking activities after the return of the military personnel [18].

Considering suggestions, military personnel's participation in peacekeeping and its effect on family, and group identification's role for stress buffering are clear, in the present study there was the first attempt to research this relation with samples-family members of military personnel who participates in a peacekeeping group in Lebanon 6 month's period. The main hypotheses formulated as following: military personnel's participation in peacekeeping operation would be negatively associated with family member's emotional stability and controllability awareness; stress's negative impact on family is dependent on family member's social (group) identification level with their family group. There are studies have found a correlation between stress and emotional well-being $(\mathrm{p}<0.001)$ [19], controllability awareness $(\mathrm{p}<0.001)$ [20]. "Controllability awareness"is defined by J.H.Todrank and E.Somer as «the extent to which an individual's responses to life situations reflect attention to distinctions between controllable and uncontrollable aspects of potential outcomes. The current study there takes account of these correlation coefficients, and proposes that if military personnel's participation has an impact on family members; social (group) identification would be a significant predictor to moderate this relationship with Kazakhstan military families.

In order to testing the hypotheses there volunteered family members of military personnel who are preparing to participate such an action ( $\mathrm{N}=94)$ and families of military personnel who have participated a peacekeeping mission $(\mathrm{N}=106)$ with total number 200. Participants were not limited by specific criteria, except that all family members' age no less than 18. Data were collected from participants with the scales of multiple - choice questionnaire. The first scale that measured their perceived stress level which participants were required to respond on questionnaire evaluated their feelings and thoughts during the last months [21]. The next scales were about evaluation of their emotional stability and controllability awareness $[22,20]$. The last questionnaire was concerned with family social (group) identification level through scale that consists of three aspects of social (group) identity, including ingroup ties, cognitive centrality and ingroup affect [23].

Before the completing data, participants were asked to read an information sheet with a consent form. They were informed of their right to withdraw from the study at any time. Furthermore, they receive instructions about their tasks during the study that would complete questionnaires, which the time length for answering the questions of 
studies takes overall thirty five minutes. In addition, they were informed via a consent form that there might be a few risk associated with the questionnaires for example, possible discomfort when answering some of the personal questions. Then asked to sign the consent form whether they agreed to the participation in the study. There was given a debriefing to them after the study.

The results of research showed that family has affected negatively by military personnel's participation in peacekeeping activity and their stress has impacted on their emotional stability and controllability awareness $(p<.01)$. However, group identification included model stress's negative affect on family members was not significant $(\mathrm{p}>$.05). That means the effect of stress on those variables reduced under the group (social) identification's condition. It is because group identification changes the mechanism depending on individual's family identification level. This means, the impact of stress on family was not significant in the presence of individual's high level group identification with their family. When individual's identification level with their family was high, their cognitive appraisal family is central and their ingroup ties and affects among members of family that caused to increase their stress level. That means, when their ingroup ties increase members of their families helps and support each other; spend a lot of time doing things together at home, also work hard at what they do in their home. This feeling of togetherness might lead to them increasing their family ingroup affect that was expressed they are proud to be a part of their family; increasing their feeling of social support; getting along well with each other members which consequently, guiding family as a central an individual's mind and decrease exposure to stress.

The effect of group identification with family members during the pre-deployment period in the prevention and reduction of stress has a higher effect compared to the pre deployment period. Furthermore, there identified military personnel's participation to the peacekeeping has negatively affected negatively to family member's controllability awareness and emotional stability more after peacekeeping deployment than the pre deployment period. That is to say, psychological support for family members is a significant tack predeployment period in order to prepare them to resist stressors, however, other periods of peacekeeping operation are stages should focus of attention on psychological support that to not increase their stress.

Although the negative affect of stress on military family controllability awareness and emotional stability, family member's group identification level has a significant variable to reduce stress level between this relationships.

To sum up, military personnel's participation to the peacekeeping activity affects on their family members' emotional stability and controllability awareness. Group identification changes the impact of the stress on family is dependent on their group identification level with their family group. Individual's high social identification with their family members is an effective preventive and coping method with peacekeeping related stress. The higher group identification family group, the lower levels of stress. The lower level of stress, the higher adaptation for a new situation and the lower negative impact on family well-being.

The importance of the research is, it gives an opportunity for an understanding of how individual's family group identification plays a significant role for family member's well-being, in particular how it decreases stress's negative affect on family of military personnel, participating in peacekeeping activity.

\section{References:-}

1. John, H. \& Newby, DSW. Positive and Negative Consequences of a Military Deployment. Military Medicine. 2005. 170. P. 815-819.

2. Gewirtz, A.H., Erbes, Ch., R., Polusny, M., A., Forgatch, M.S. \& DeGarmo, D.S. Helping military families through the deployment process: Strategies to support parenting. Professional Psychology: Research and Practice. 2011. 42. P. 56-62. doi: 1-.1-37/a0022345.

3. Lazarus, R.S. \& Folkman, S. Stress, appraisal and coping. New York: Springer Press, 1984.

4. Bartone, P. Stress in the Military setting, in C. Cronin (Ed.). Military Psychology: An Introduction. Needham Heights: Simon and Schuster Custom Publishing. 1998. P. 113-146.

5. Pincus, SH. \& Nam, TS. Psychological Aspects of Deployment: The Bosnian Experience. JAMEDD. 1999. 8(99). P. 38-44.

6. Wiens, T. W. \& Boss, P. Maintaining Family Resiliency Before, During, and After Military Separation. In C. A. Castro, A. B. Adler, \& T. W. Britt (Eds.), The Military Life. Military life: The psychology of serving in peace and combat: The military family. Westport, CT,: Praeger Security International. 2006. 3. P. 13-38. 
7. Issimova, A. The role of social identity for coping with work related stress on family functioning. Pedagogy \& Psychology: Theory and Practice. 2019. 2. P. 67-70.

8. McCubbin, H.I. Integrating coping behavior in family stress theory. Journal of Marriage and the Family. 1979. 41. P. 237-244.

9. Baider, L., Ever-Hadani, P., Goldzweig, G., Wygoda MR, \& Peretz, T. Is perceived family support a relevant variable in psychological distress? Journal of Psychosomatic research. 2003. 55(5). P. 453-460.

10. Kraskovskaia, V. \& Racu, J. Interrelation between personal characteristics and stress at the military personnel in the conditions of the military service. Psihologie.Pedagogie Speciala. Asistents Sociala. 2017. 47(2). P.85-92.

11. Drazic, R. Military psychologists necessary as Serbian soldiers prepare for Peacekeeping missions. 2007. P. 121-125. doi: 10.5937/vojdelo1704121D.

12. Rosebush, P. A. Psychological intervention with military personnel in Rwanda. Military Medicine. 1998. 163(8). P. 559-563.

13. Sheppard, S.C., Malatras, J.W. \& Israel, A.C. The impact of Deployment on US Military Families. American Psychologist. 2010. 65. P. 599-609.

14. Greenberg, N., Thomas, S.L., Iversen, A., Unwin, C., Hull, L., \& Wessely, S. Do military peacekeepers want to talk about their experiences? Perceived psychological support of UK military peacekeepers on return from deployment. Journal of Mental Health. 2003. 12. P. 561-569.

15. Taifel, H. Social categorization, social identity and social comparison. In H.Taifel (Ed.), Differentiation between social groups: Studies in the social psychology of ingroup relations London: Academic Press. 1978. P. 61-76.

16. Haslam, SA, O’Brien, A., Jetten, J., Volmedal, K. \& Penna S. Taking the strain: social identity, social support and the experience of stress. British Journal Social Psychology. 2005. 44(3). P. 355-370.

17. Mansfield, A.J., Kaufman, J.S., Marshal, SW, Gaynes, BN, Morrissey, JP \& Engel CC. Deployment and the use of mental health services among U.S. Army wives. New England Journal of Medicine. 2010. 362. P. 101-109.

18. Racu, M.S. Psychological aspect of peacekeeping operations. Industrial Psychiatry. 2014. 23(2). P. 149-156.

19. Pflanz, S. \& Sonner, S. (2002). Work stress in the military: prevalence, causes, and relationship to emotional health. Military Medicine. 2002. 167(11). P. 877-882.

20. Todrank J.,H. \& Somer, E. Characterizing stress tolerance: controllability awareness and its relationship to perceived stress and reported health // Personality and individual differences. 2002. 33. P. 883-895.

21. Cohen, S. \& Kamarck, T. A global measure of perceived stress // Journal of Health and Social Behaviour. 1994. 24(4). P. 385-396.

22. Chaturvedi, M. \& Chander R. Development of emotional stability scale. Industrial Psychiatry Journal. 2010. 19. P. 37-40. doi: 10.4103/0972-6748.77634.

23. Cameron, J. A three factor model of social identity. Self and Identity. 2004.- 3(3). P. 239-262. doi:10.1080/13576500444000047. 